\title{
Right atrial appendage pacing in cardiac resynchronization therapy - haemodynamic consequences of interatrial conduction delay
}

\author{
Alicja Dąbrowska-Kugacka, Ewa Lewicka, Anna Faran, Dariusz Kozłowski, Maciej Kempa, \\ Grzegorz Raczak
}

Department of Cardiology and Electrotherapy, Medical University of Gdansk, Poland

Submitted: 8 March 2011

Accepted: 23 June 2011

Arch Med Sci 2011; 7, 4: 728-731

DOI: 10.5114/aoms.2011.24146

Copyright (๑) 2011 Termedia \& Banach

\section{Abstract}

The present case report describes a patient with an artificial mitral valve and dual chamber pacemaker implanted due to perioperative complete atrioventricular block. One year later an upgrade to cardiac resynchronization therapy (CRT) combined with ICD function was performed due to significant progression of heart failure symptoms. Beneficial effects of CRT are demonstrated, but unfavourable haemodynamic consequences of right atrial appendage pacing are also underlined. Important interatrial conduction delay during atrial paced rhythm resulted in a significant time difference between optimal sensed and paced atrio-ventricular delay (AVD). This report provides a practical outline how to determine the interatrial delay and the sensed-paced AVD offset under echocardiography in patients treated with CRT.

Key words: cardiac resynchronization therapy, atrio-ventricular delay, echocardiography, atrial pacing, heart failure.

\section{Introduction}

Cardiac resynchronization therapy (CRT) is an effective treatment in patients with medically refractory heart failure, severe left ventricular (LV) dysfunction, and prolonged QRS duration [1]. The response to CRT depends on several factors, including device settings. Optimally programmed atrioventricular delay (AVD) can affect the acute haemodynamic response and may influence the magnitude of clinical improvement under chronic pacing [2]. There are scarce data regarding the AVD optimization in CRT patients during atrial-paced compared with atrial-sensed biventricular pacing. The present case report shows how to determine the optimal AVD during echocardiographic examination and underlines possible marked differences between atrial-sensed and atrial-paced rhythms in CRT patients.

\section{Case report}

A 55-year-old white male had an artificial mitral valve implanted due to severe mitral insufficiency in the course of the degenerative process, and a dual chamber pacemaker because of perioperative third degree atrio-ventricular block. One year later he was admitted to our hospital because of chronic heart failure exacerbation (NYHA III). Before admission

\author{
Corresponding author: \\ Alicja Dąbrowska-Kugacka MD \\ Department of Cardiology \\ and Electrotherapy \\ Medical University of Gdansk \\ 7 Dębinki \\ 80-211 Gdańsk, Poland \\ Phone: +48583493910 \\ Fax: +48583493920 \\ E-mail: \\ adabrowska@gumed.edu.pl
}


Table I. Clinical and echocardiographic parameters before and after upgrading to cardiac resynchronization therapy (CRT) and device optimization

\begin{tabular}{|c|c|c|c|c|c|c|}
\hline \multirow[t]{2}{*}{ Parameters } & & \multirow{2}{*}{$\begin{array}{l}\text { Before CRT } \\
\text { implantation }\end{array}$} & \multicolumn{4}{|c|}{7 days after CRT } \\
\hline & & & $\begin{array}{l}\text { Nominal } \\
\text { VVD/AVD }\end{array}$ & $\begin{array}{c}\mathrm{LV}+30 \\
\text { Nominal AVD }\end{array}$ & $\begin{array}{l}\mathrm{LV}+30 \\
\text { Atrial sensed } \\
\text { rhythm } \\
\text { (optimal AVDs } \\
30 \mathrm{~ms} \text { ) }\end{array}$ & $\begin{array}{c}\mathrm{LV}+30 \\
\text { Atrial paced } \\
\text { rhythm } \\
\text { (optimal AVDp } \\
190 \mathrm{~ms} \text { ) }\end{array}$ \\
\hline Heart failure functional class & (NYHA) & III & & & $\|$ & \\
\hline Heart rate $[\mathrm{bpm}]$ & & 67 & & $70-72$ & & 75 \\
\hline Left atrial dimension [mm] & $(\mathrm{N}: 19-40)$ & 50 & 48 & & & \\
\hline IVS wall thickness [mm] & $(\mathrm{N}: 6-11)$ & 13 & 13 & & & \\
\hline Posterior wall thickness [mm] & $(\mathrm{N}: 6-11)$ & 13 & 13 & & & \\
\hline LVEDD $[\mathrm{mm}]$ & $(\mathrm{N}: 37-56)$ & 62 & 62 & & & \\
\hline LVESD [mm] & $(\mathrm{N}: 21-40)$ & 47 & 45 & & & \\
\hline LVEDVI [ml/m²] & (N: 50-90) & 75 & 75 & & & \\
\hline LVEDV/LVESV [ml] & & $128 / 93$ & $128 / 83$ & & & \\
\hline LV ejection fraction [\%] & (N: 59-74) & 27 & 35 & & & \\
\hline Right ventricle [mm] & $(N<28)$ & 29 & 29 & & & \\
\hline $\mathrm{RVSP}[\mathrm{mmHg}]$ & $(\mathrm{N}<33)$ & 33 & 33 & & & \\
\hline \multicolumn{7}{|l|}{ Haemodynamic measurements: } \\
\hline Aortic VTI [cm] & & 17.5 & 22.0 & 22.3 & 22.5 & 21.7 \\
\hline $\mathrm{CO}[\mathrm{l} / \mathrm{min}]$ & & 2.35 & 3.10 & 3.21 & 3.24 & 3.25 \\
\hline \multicolumn{7}{|l|}{ Dyssynchrony assessment: } \\
\hline $\mathrm{DFT}_{\mathrm{LV}}[\mathrm{ms} / \% \mathrm{RR}]$ & $(\mathrm{N}>40 \%)$ & $420 / 47$ & $260 / 31$ & $260 / 31$ & $313 / 38$ & $360 / 45$ \\
\hline $\mathrm{IAD}[\mathrm{ms}]$ & $(N<30)$ & 50 & \multicolumn{2}{|c|}{ Monophasic mitral inflow } & 50 & 140 \\
\hline $\mathrm{IVMD}[\mathrm{ms}]$ & $(N<20)$ & 60 & 37 & 20 & 20 & 20 \\
\hline $\begin{array}{l}\text { Septo-posterior wall } \\
\text { motion delay [ms] }\end{array}$ & $(\mathrm{N}<70)$ & 250 & 200 & 180 & 180 & 180 \\
\hline \multicolumn{2}{|c|}{ Paradoxical motion of the distal IVS } & + & - & - & - & - \\
\hline \multicolumn{2}{|c|}{ Paradoxical apical motion ("apical shuffle") } & + & - & - & - & - \\
\hline
\end{tabular}

IVS - interventricular septum, LV - left ventricle, LVEDD/LVESD - LV end-diastolic/end-systolic diameter, LVEDVI - LV end-diastolic volume index, LVEDV/LVESV - LV end-diastolic/end-systolic volume, VTI - velocity time integral, RVSP - right ventricular systolic pressure, DFT $-L V$ diastolic filling time (in $m$ s and as percentage of the RR interval), IAD - interatrial delay, IVMD - interventricular mechanical delay, nominal VVD/AVD simultaneous biventricular pacing/atrio-ventricular delay paced (AVDp) $180 \mathrm{~ms} / \mathrm{sensed}$ (AVDs) $120 \mathrm{~ms}, L V+30-L V$ pre-excitation of $30 \mathrm{~ms}$

the patient was treated with bisoprolol $5 \mathrm{mg}$, perindopril $10 \mathrm{mg}$, spironolactone $25 \mathrm{mg}$ and furosemide $80 \mathrm{mg}$. Intravenous furosemide (120 mg) and spironolactone (100 mg) were administered. The ECG showed permanent VAT pacing (atrially triggered ventricular pacing) of 67 bpm. Echocardiography demonstrated normal artificial mitral valve function, depressed LV ejection fraction (27\%), enlarged LV end-diastolic $(62 \mathrm{~mm})$ and left atrial diameter $(50 \mathrm{~mm})$, preserved atrio-ventricular synchrony, but prominent interventricular and intra-LV dyssynchrony (Table I). Coronary angiography revealed no abnormalities. Five days after admission the patient successfully underwent the
DDD pacemaker upgrade to CRT-D (Boston Scientific, Cognis 100-D) with the defibrillating lead placed in the right ventricular apex, LV lead in the postero-lateral vein and the previously implanted atrial lead remained in the right atrial appendage (RAA). A week after implantation the patient improved significantly (NYHA II), the LV ejection fraction was 33\%, and mechanical dyssynchrony diminished (Table I). The device was optimized under echocardiography. The greatest aortic velocity time integral and the lowest interventricular mechanical delay (IVMD) were obtained with $30 \mathrm{~ms}$ LV pre-excitation. The resting AVD was optimized to provide the longest transmitral filling time without A wave truncation 
from pulsed wave Doppler analysis of the LV filling [2]. The optimal AVD during atrial-sensed rhythm (70-72 bpm) was $30 \mathrm{~ms}$, which was the shortest AVD available in the device (Figure 1). In contrast, the optimal AVD during atrial-paced rhythm (75 bpm) was as long as $190 \mathrm{~ms}$ (Figure 2). Biventricular capture with AVD 190 ms was confirmed by the constant value of IVMD and unchanged QRS morphology on the ECG. Interatrial delay (IAD) during atrial-paced rhythm (75 bpm) was $140 \mathrm{~ms}$ (Figure 3). During atrial- sensed rhythm the IAD was $50 \mathrm{~ms}$. In the Cognis 100-D device the greatest sensed-paced offset of the AVD is $100 \mathrm{~ms}$. The CRT-D device was programmed in the DDD mode with a basic rate of $60 \mathrm{bpm}$ to promote the VAT pacing, with the sensed AVD of $30 \mathrm{~ms}$ and paced AVD of $130 \mathrm{~ms}$. As Holter monitoring had revealed so far predominant atrial-sensed rhythm (80\% in the VAT mode) we concentrated on the optimal sensed AVD. Additionally, as the incidence of atrial fibrillation in CRT recipients may be related to the
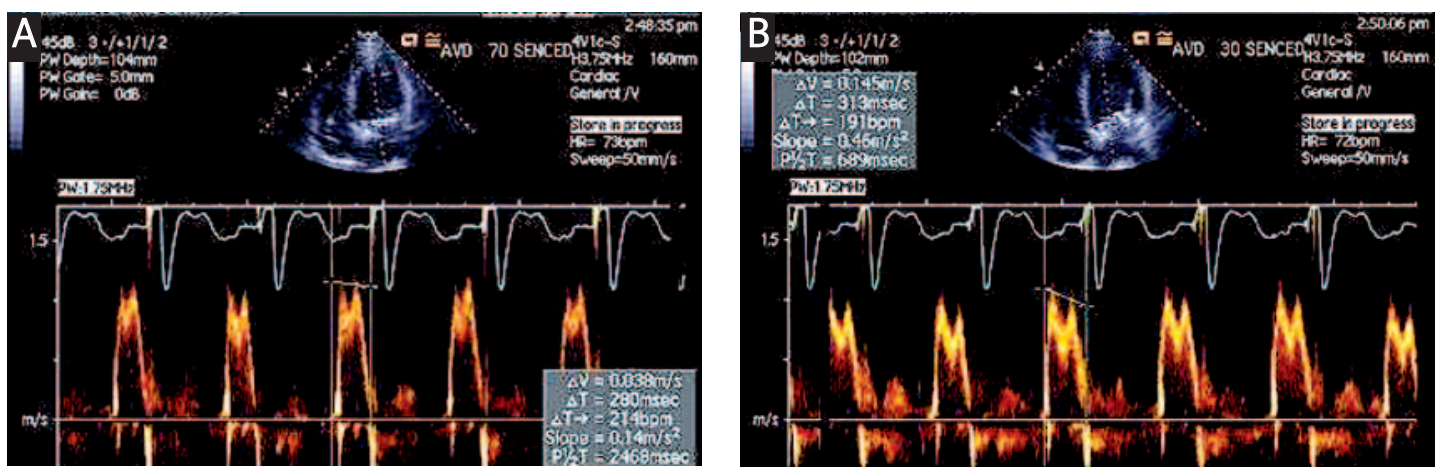

Figure 1. Atrio-ventricular delay optimization during the atrial-sensed rhythm (70-72 bpm) according to mitral inflow velocity waveforms. A - AVD of 70 ms was too long, as diastolic filling time (DFT ${ }_{\text {IV }}$ ) was only $280 \mathrm{~ms}$ ( $34 \%$ of the RR interval), $\mathrm{E}$ and A wave fusion was present. B - with AVD of $30 \mathrm{~ms}$ the DFT LV was prolonged to $313 \mathrm{~ms}$ ( $38 \%$ of the RR interval)
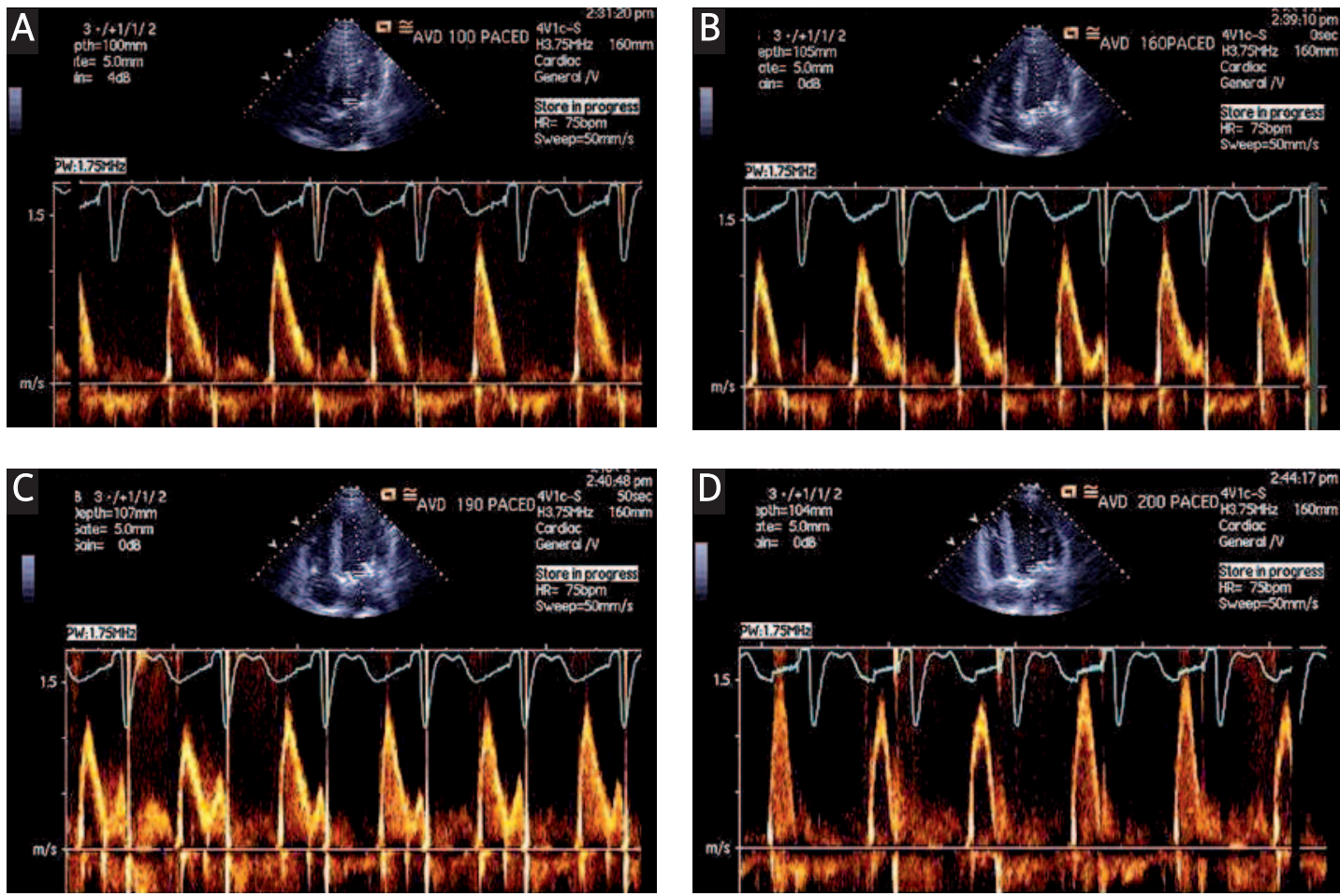

Figure 2. Atrio-ventricular delay optimization during the atrial-paced rhythm (75 bpm) according to mitral inflow velocity waveforms. A - AVD paced at $100 \mathrm{~ms}$ was too short - monophasic mitral inflow was present, B - starting with AVD paced at 160 ms a tiny atrial A-wave appeared, C - AVD paced at 190 ms was optimal since it provided the longest DFT $T_{L V}$ without atrial A-wave truncation, D - with AVD paced at $200 \mathrm{~ms}$ and longer, truncation of the atrial A-wave was present 

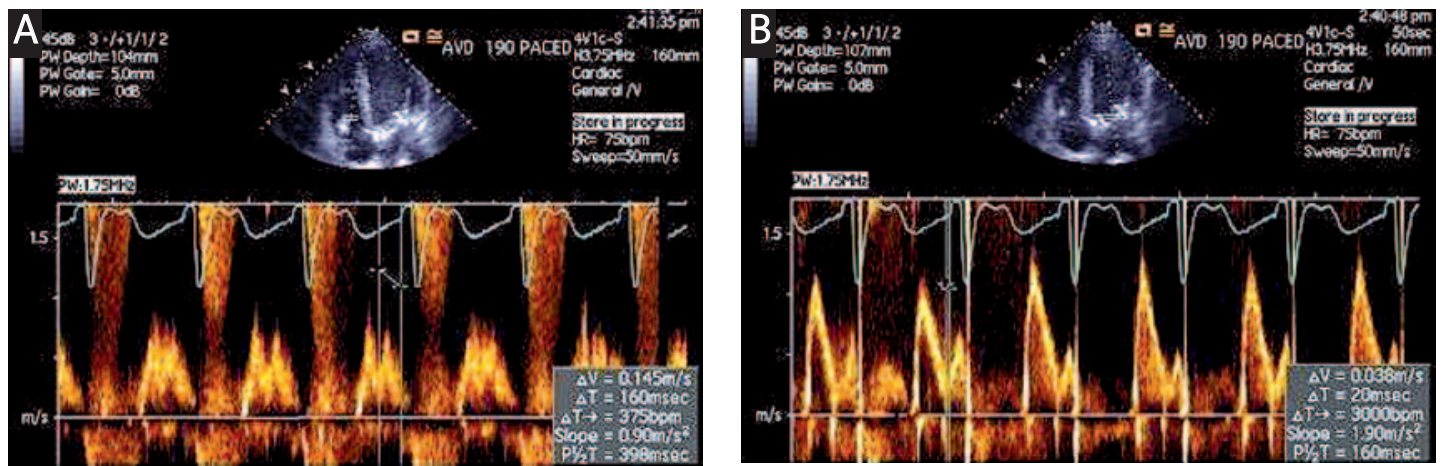

Figure 3. Interatrial delay assessment during the atrial-paced rhythm (75 bpm). Registration of the tricuspid (A) and mitral (B) inflow during apnoea and the difference between the beginning of the right and left atrial A-wave was calculated: $160 \mathrm{~ms}-20 \mathrm{~ms}=140 \mathrm{~ms}$

percentage of atrial paced rhythm, we decided to promote native atrial rhythm in this patient [3] After 6 months the patient was still in NYHA II.

\section{Discussion}

Cardiac resynchronization therapy is an effective treatment in heart failure patients, especially if significant mechanical dyssynchrony is present [4]. Unfortunately, one-third of these patients do not derive clinical benefit from CRT. Atrial conduction abnormalities and suboptimal device programming are factors which determine the final outcome [5].

After un upgrade to CRT the patient's functional class, mechanical synchrony and LV ejection fraction improved significantly. However, optimization of the AVD during atrial sensed and paced rhythm revealed a huge difference between these two settings. The nominal value for atrial sensed-paced offset in the Cognis 100-D device is $60 \mathrm{~ms}$. Previous studies [6] have underlined that even greater offset could be haemodynamically beneficial in CRT patients, but it varies widely among patients. The RAA is the standard site for atrial lead implantation, but pacing from this region may induce and/or aggravate pre-existing interatrial conduction disturbances. Physiological mechanical IAD determined by echocardiography is less than $30 \mathrm{~ms}$ [7]. In our patient the native IAD, determined during atrial sensed-rhythm, was prolonged to $50 \mathrm{~ms}$ and it was further elongated to $140 \mathrm{~ms}$ during atrialpaced rhythm. It resulted in a $160 \mathrm{~ms}$ time difference between the optimal paced and sensed AVD, which was impossible to program. In our patient, apart from the atrial pacing site, left atrial enlargement in the course of mitral insufficiency could have been a factor of the IAD prolongation. Atrial lead placement in the interatrial septum (preferentially in the Bachmann's bundle region) could have obviated the huge sensed-paced AVD offset [7].

\section{Acknowledgments}

The authors declare no conflict of interests.

\section{References}

1. Bristow MR, Saxon LA, Boehmer J, et al. Cardiacresynchronization therapy with or without an implantable defibrillator in advanced chronic heart failure. N Engl J Med 2004; 350: 2140-50.

2. Bhan A, Kapetanakis S, Monaghan MJ. Optimization of cardiac resynchronization therapy. Echocardiography 2008; 25: 1031-9.

3. Adelstein E, Saba S. Right atrial pacing and the risk of postimplant atrial fibrillation in cardiac resynchronization therapy recipients. Am Heart J 2008; 155: 94-9.

4. Shen X, Aronow WS, Anand K, et al. Clinical research evaluation of left ventricular dyssynchrony using combined pulsed wave and tissue Doppler imaging. Arch Med Sci 2010; 6: 519-25.

5. Piotrowski G, Szymański P, Banach M, et al. Left atrial and left atrial appendage systolic function in patients with postmyocardial distal blocks. Arch Med Sci 2010; 6: 892-9.

6. Gold MR, Niazi I, Giudici M, et al. Acute hemodynamic effects of atrial pacing with cardiac resynchronization therapy. J Cardiovasc Electrophysiol 2009; 20: 894-900.

7. Dąbrowska-Kugacka A, Lewicka-Nowak E, Ruciński P, Kozłowski D, Raczak G, Kutarski A. Single-site Bachmann's bundle pacing is beneficial while coronary sinus pacing results in echocardiographic right heart pacemaker syndrome in brady-tachycardia patients. Circulation J 2010; 74: $1308-15$ 